\title{
Preparation and Characterization of Magnetic Mesoporous Bioactive Glass/Carbon Composite Scaffolds
}

\author{
Min Zhu, ${ }^{1}$ Jianhua Zhang, ${ }^{1}$ Yinghong Zhou, ${ }^{2}$ Yunfei Liu, ${ }^{3}$ Xing He, ${ }^{1}$ \\ Cuilian Tao, ${ }^{1}$ and Yufang $\mathrm{Zhu}^{1}$ \\ ${ }^{1}$ School of Materials Science and Engineering, University of Shanghai for Science and Technology, 516 Jungong Road, \\ Shanghai 200093, China \\ ${ }^{2}$ Institute of Health \& Biomedical Innovation, Queensland University of Technology, Brisbane QLD 4059, Australia \\ ${ }^{3}$ College of Materials Science and Engineering, Nanjing University of Technology, 5 Xinmofan Road, Nanjing 210009, China
}

Correspondence should be addressed to Yufang Zhu; yfzhu@usst.edu.cn

Received 2 May 2013; Revised 16 June 2013; Accepted 17 June 2013

Academic Editor: Nurettin Sahiner

Copyright (C) 2013 Min Zhu et al. This is an open access article distributed under the Creative Commons Attribution License, which permits unrestricted use, distribution, and reproduction in any medium, provided the original work is properly cited.

\begin{abstract}
The magnetic Fe-MBG/C composite scaffolds with enhanced mechanical strength and multifunctionality have been successfully prepared. The study showed that the Fe-MBG/C composite scaffolds with the porosity of ca. $80 \%$ had interconnected macropores $(200-500 \mu \mathrm{m})$ and mesopores $(3.7-4.4 \mathrm{~nm})$ and significantly enhanced the compressive strength compared to the pure MBG scaffolds. Importantly, the Fe-MBG/C composite scaffolds exhibited good bioactivity and sustained drug release property. At the same time, the Fe-MBG/C composite scaffolds could generate heat to raise the temperature of surrounding environment in an alternating magnetic field due to their superparamagnetic behavior. Therefore, the magnetic Fe-MBG/C composite scaffolds could form a multifunctional platform with bone regeneration, magnetic hyperthermia, and local drug delivery and have more potential for use in the regeneration of the critical-sized bone defects caused by bone tumors.
\end{abstract}

\section{Introduction}

Mesoporous bioactive glass (MBG), as a bioactive material, has drawn growing interest in bone regeneration in recent years $[1,2]$. As a result of its high specific surface area, large pore volume, and mesoporous structure, MBG exhibits the enhanced bone-forming bioactivity, degradation and drug delivery properties, compared to the conventional bioactive glass (BG) [3-10].

In order to repair large bone defects, the scaffolds mimicking the three-dimensional (3D) tissue structure have been considered as the most promising solution, because ideal 3D scaffolds with a highly interconnected macroporous network facilitate cell migration, proliferation, nutrients delivery, bone ingrowth, and eventually vascularization [11-13]. To date, many efforts have been made to develop 3D MBG scaffolds for large bone regeneration [14-25]. For example, Yun et al. synthesized the hierarchically mesoporous-macroporous 3D BG scaffolds by combining sol-gel, double polymers templating, and rapid prototyping technique, and the $\mathrm{MBG}$ scaffolds exhibited better in vitro bioactivity compared to the normal BG scaffolds $[14,15]$. We have successfully prepared the $\mathrm{CaO}-\mathrm{SiO}_{2}-\mathrm{P}_{2} \mathrm{O}_{5}$ MBG scaffolds by a combination of polyurethane sponge and P123 surfactant as cotemplates and evaporation-induced self-assembly (EISA) process [17, 18]. The results indicated that the chemical compositions influenced the apatite forming ability and cell attachment [17]. Wu et al. used the same strategy to prepare the iron, boron, strontium, copper, and cobalt-containing $\mathrm{CaO}-\mathrm{SiO}_{2}$ $\mathrm{P}_{2} \mathrm{O}_{5}$ MBG scaffolds for bone tissue engineering [19-23].

However, major drawback of the above mentioned MBG scaffolds is low mechanical strength due to their brittle characteristic. Therefore, the composite scaffolds of MBG and other components are being developed with the aim of increasing the mechanical strength. For example, $\mathrm{Wu}$ et al. prepared silk-modified $\mathrm{MBG}$ scaffolds by coating silk on the pore walls surfaces [26]. The results indicated that silk modification did not change the interconnected pore network and improved mechanical strength $(250 \mathrm{KPa})$ and BMSC proliferation and differentiation. We proposed 
a strategy to incorporate zirconium $(\mathrm{Zr})$ into the $\mathrm{CaO}$ $\mathrm{SiO}_{2}-\mathrm{P}_{2} \mathrm{O}_{5}$ MBG scaffolds, and the Zr-incorporated MBG scaffolds enhanced the compressive strength $(214 \mathrm{KPa})$ and also exhibited a better physiochemical and biological properties [27]. Other researchers focused on the preparation of the MBG/polymer composite scaffolds [28-31]. Yun et al. prepared the MBG/PCL composite scaffolds by using rapid prototyping technique [28]. The combination of $\mathrm{MBG}$ and PCL brings about a significant enhancement of the molding capacity, mechanical property, and in vitro boneforming bioactivity of the scaffolds compared to the pure PCL scaffolds. Li et al. and $\mathrm{Su}$ et al. reported the preparation of MBG/polycaprolactone (PCL) and MBG/polyamide composite scaffolds by using a solvent-casting-particulateleaching method, respectively [29, 30]. But this method was difficult to control the mechanical stability and both the structure and interconnectivity of pores, which may limit their application in terms of cell migration in tissue engineering.

It has been demonstrated that carbon composites have great prospect in bone repair field due to the excellent mechanical property, especially their elastic modulus close to that of human bones [32]. Furthermore, carbon materials are biocompatible and had been applied widely to clinic. For example, the carbon materials made by isothermal chemical vapor infiltration had represented as artificially heart valve materials with the highest level [33]. On the other hand, carbon materials, such as carbon nanotubes and carbon fibers, are often used to reinforce the mechanical characteristics of bioceramics [34, 35]. For example, Boccaccini et al. reported the coating of $3 \mathrm{D}$ porous Bioglass scaffolds with multiwalled carbon nanotubes (CNTs), and the presence of CNTs enhanced the mechanical strength of the scaffolds [35]. We hypothesized that the formation of MBG/C composite scaffolds would enhance the mechanical strength and, at the same time, would not influence the mesoporous structure and bioactivity of the MBG scaffolds. As far as we know there are no reports on the development of the $\mathrm{MBG} / \mathrm{C}$ composite scaffolds with enhanced mechanical strength for bone regeneration.

On the other hand, many research groups have tried to design magnetic bioactive composites to repair bone defects caused by bone tumors, such as magnetic bioactive glass ceramics, CaP ceramics and composites [36-43]. Magnetic bioactive composites can be used for hyperthermia in an alternating magnetic field to destroy the tumor cells, because cancer cells generally perish around $43^{\circ} \mathrm{C}$ due to hemorrhage, stasis, and vascular occlusion, whereas normal cells are not damaged until higher temperature $[41,42]$. At the same time, the bioactive matrices could induce bone regeneration. Recently, we reported a type of magnetic $\mathrm{Fe}_{3} \mathrm{O}_{4}-\mathrm{CaO}-\mathrm{SiO}_{2}-$ $\mathrm{P}_{2} \mathrm{O}_{5}$ MBG scaffolds, which formed a potential multifunctional platform, combining bone regeneration, magnetic hyperthermia, and local drug delivery [43]. However, their low mechanical strength (ca. $64 \mathrm{kPa}$ ) was similar to that of the conventional $\mathrm{CaO}-\mathrm{SiO}_{2}-\mathrm{P}_{2} \mathrm{O}_{5} \mathrm{MBG}$ scaffolds [17-23].

In this study, we proposed an improved strategy to prepare magnetic MBG/C composite scaffolds with enhanced mechanical strength by polyurethane (PU) sponge

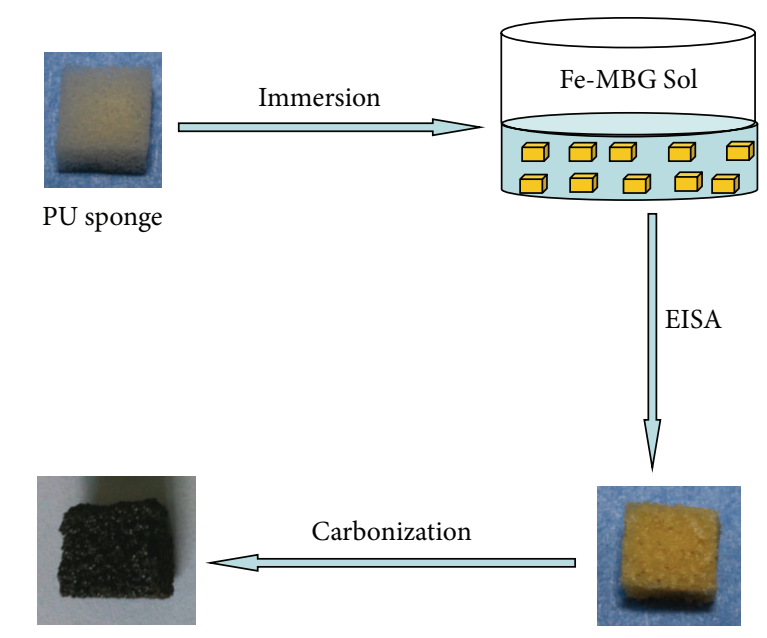

Fe-MBG/C scaffold

Fe-MBG/PU

FIgURE 1: The schematic procedure for the preparation of the Fe$\mathrm{MBG} / \mathrm{C}$ composite scaffolds.

templating method and the carbonization process. As shown in Figure 1, the first step involved the preparation of Fecontaining MBG (Fe-MBG) sol using P123 as structuredirecting agent and the immersion of PU sponges in the FeMBG sol. In the next step, the PU sponges adsorbed with Fe-MBG sol could form the Fe-MBG/PU composite scaffolds after evaporation-induced self-assembly (EISA) process. Finally, magnetic Fe-MBG/C composite scaffolds were obtained after the carbonization under argon atmosphere. To the best of our knowledge, reports on such strategy to prepare magnetic MBG/C composite scaffolds have not been found before.

\section{Experimental Methods}

2.1. Preparation of Magnetic Fe-MBG/C Composite Scaffolds. Magnetic Fe-MBG/C composite scaffolds were prepared following our previously reported method after some modification [17, 31]. As an example, to prepare magnetic Fe-MBG/C composite scaffolds containing 10\% Fe (10FeMBG/C), typically $4.0 \mathrm{~g}$ of P123 (Mw $=5800$, Aldrich), $6.7 \mathrm{~g}$ of tetraethyl orthosilicate (TEOS, 98\%, Acros), $0.47 \mathrm{~g}$ of calcium nitrate $\left(\mathrm{Ca}\left(\mathrm{NO}_{3}\right)_{2} \cdot 4 \mathrm{H}_{2} \mathrm{O}\right), 1.08 \mathrm{~g}$ of ferric chloride hexahydrate $\left(\mathrm{FeCl}_{3} \cdot 6 \mathrm{H}_{2} \mathrm{O}\right), 0.73 \mathrm{~g}$ of triethyl phosphate (TEP, $99.8 \%$, Sigma-Aldrich), and $1.0 \mathrm{~g}$ of $0.5 \mathrm{M} \mathrm{HCl}$ were dissolved in $60 \mathrm{~g}$ ethanol and stirred at room temperature for 1 day (molar ratio of $\mathrm{Fe}: \mathrm{Ca}: \mathrm{Si}: \mathrm{P}=10: 5: 80: 5$ ). Afterwards, the PU sponges (20ppi, Shanghai Zhengyang) were completely immersed into the sol for $10 \mathrm{~min}$ and transferred to a petri dish to squeeze out the excess sol. After evaporating the solution for $12 \mathrm{~h}$ at room temperature, the same procedure was repeated for 8 times. When the samples were completely dry, they were carbonized at $700^{\circ} \mathrm{C}$ (ramp of $2^{\circ} \mathrm{C} / \mathrm{min}$ ) under argon atmosphere for $6 \mathrm{~h}$ to obtain 10Fe-MBG/C composite scaffolds. The MBG/C composite scaffolds without $\mathrm{Fe}(0 \mathrm{Fe}-$ $\mathrm{MBG} / \mathrm{C})$ and with $5 \% \mathrm{Fe}(5 \mathrm{Fe}-\mathrm{MBG} / \mathrm{C})$ were prepared by the same method. The chemical compositions and the amounts 
TABLE 1: Chemical composition and the amounts of the reagents of different MBG sol solutions.

\begin{tabular}{lcccccccc}
\hline Sample names & $\begin{array}{c}\text { Molar ratio } \\
\mathrm{Fe}: \mathrm{Ca}: \mathrm{Si}: \mathrm{P}\end{array}$ & $\begin{array}{c}\mathrm{P} 123 \\
(\mathrm{~g})\end{array}$ & $\begin{array}{c}\text { TEOS } \\
(\mathrm{g})\end{array}$ & $\begin{array}{c}\mathrm{Ca}\left(\mathrm{NO}_{3}\right)_{2} \cdot 4 \mathrm{H}_{2} \mathrm{O} \\
(\mathrm{g})\end{array}$ & $\begin{array}{c}\mathrm{FeCl}_{3} \cdot 6 \mathrm{H}_{2} \mathrm{O} \\
(\mathrm{g})\end{array}$ & $\begin{array}{c}\mathrm{TEP} \\
(\mathrm{g})\end{array}$ & $\begin{array}{c}0.5 \mathrm{M} \mathrm{HCl} \\
(\mathrm{g})\end{array}$ & $\begin{array}{c}\mathrm{C}_{2} \mathrm{H}_{5} \mathrm{OH} \\
(\mathrm{g})\end{array}$ \\
\hline 0Fe-MBG & $0: 15: 80: 5$ & 4 & 6.7 & 1.40 & 0 & 0.73 & 1.0 & 60 \\
5Fe-MBG & $5: 10: 80: 5$ & 4 & 6.7 & 0.94 & 0.54 & 0.73 & 1.0 & 60 \\
10Fe-MBG & $10: 5: 80: 5$ & 4 & 6.7 & 0.47 & 1.08 & 0.73 & 1.0 & 60 \\
\hline
\end{tabular}

of reagents used to prepare different Fe-MBG sol solutions are listed in Table 1.

The wide angle X-ray diffraction (WAXRD) patterns were obtained on a Stoe Stadi P powder diffractometer equipped with a curved germanium (111) monochromator and linear PSD using $\mathrm{Cu} \mathrm{K} \alpha 1$ radiation (1.5405 $\AA$ ) in transmission geometry. Scanning electron microscopy (SEM) was carried out with a FEI Quanta 450 field emission scanning electron microscope. Transmission electron microscopy (TEM) was performed with a JEM-2010 UHR electron microscope operated at an acceleration voltage of $200 \mathrm{kV}$. $\mathrm{N}_{2}$ adsorptiondesorption isotherms were obtained on a Quadrasorb SI automated surface area and pore size analyzer at $-196^{\circ} \mathrm{C}$ under continuous adsorption condition. Brunauer-EmmettTeller (BET) and Barrett-Joyner-Halenda (BJH) methods were used to determine the surface area, the pore volume, and the pore size distribution. Magnetic measurement was performed using a vibrating sample magnetometer (VSM).

2.2. Porosity and Mechanical Strength of Magnetic Fe-MBG/C Composite Scaffolds. The porosity of magnetic Fe-MBG/C scaffolds was measured using Archimedes' principle: magnetic MBG/C scaffolds with a size of $5 \times 5 \times 5 \mathrm{~mm}$ were used for the measurement, and water was used as liquid medium. The porosity $(P)$ was calculated according to the following formulation $P=\left(W_{\text {sat }}-W_{\text {dry }}\right) /\left(W_{\text {sat }}-W_{\text {sus }}\right) \times 100 \%$, where $W_{\text {dry }}$ is the dry weight of magnetic Fe-MBG/C scaffolds, $W_{\text {sus }}$ is the weight of magnetic MBG/C scaffolds suspended in water, and $W_{\text {sat }}$ is the weight of magnetic MBG/C scaffolds saturated with water.

The compressive strength of the $5 \times 5 \times 5 \mathrm{~mm}$ sized magnetic Fe-MBG/C scaffolds was tested using a Zwick static materials testing machine $(5 \mathrm{kN})$ at a cross head speed of $0.5 \mathrm{~mm} / \mathrm{min}$.

2.3. Apatite Formation of Magnetic Fe-MBG/C Composite Scaffolds in Simulated Body Fluids. To investigate the apatite formation ability of magnetic MBG/C scaffolds, simulated body fluid (SBF) was prepared and buffered at $\mathrm{pH} 7.4$ with tris(hydroxymethyl)aminomethane $\left[\left(\mathrm{CH}_{2} \mathrm{OH}\right)_{3} \mathrm{CNH}_{2}\right]$ and hydrochloric acid ( $\mathrm{HCl}$ ) according to Kokubo's method [44]. Generally, magnetic Fe-MBG/C scaffolds were soaked in SBF solution in a polyethylene bottle at $37^{\circ} \mathrm{C}$ for different periods, and the ratio of the solution volume to the scaffold mass was $200 \mathrm{~mL} / \mathrm{g}$. After soaking, magnetic MBG/C scaffolds were collected from SBF solution, rinsed with ethanol, and dried. SEM observation was used to study the apatite formation on the surfaces of magnetic Fe-MBG/C scaffolds.
2.4. Cytotoxicity Evaluation of Magnetic Fe-MBG/C Composite Scaffolds. To investigate the cytotoxicity of magnetic FeMBG/C composite scaffolds, human bone mesenchymal stem cells (BMSCs) and MTT assay were used in this study. Isolation and culture of BMSCs were conducted following previously published protocols [22]. BMSCs were cultured on $5 \times 5 \times 5 \mathrm{~mm}$ scaffolds placed in 96-well culture plates, at an initial density of $1 \times 10^{5}$ cells/scaffold. For the next $3 \mathrm{~h}, 100 \mu \mathrm{L}$ of growth medium was carefully added to the base of the culture plate every $20 \mathrm{~min}$, until there was enough growth medium to cover the scaffold. MTT assay was performed in triplicate according to the previous study protocol [23]. Briefly, three cell/scaffold constructs from each group (0Fe-MBG/C, 5Fe-MBG/C, and 10Fe-MBG/C) were cultured in growth medium for 1,3 , and 7 days. $40 \mu \mathrm{L}$ of $0.5 \mathrm{mg} / \mathrm{mL}$ of MTT solution (Sigma-Aldrich) was added to each construct with $360 \mu \mathrm{L}$ growth medium at each time point. After incubated for $4 \mathrm{~h}$ at $37^{\circ} \mathrm{C}$, the medium was removed and the formazan product was solubilized in $200 \mu \mathrm{L}$ of dimethyl sulfoxide (DMSO). An aliquot of $100 \mu \mathrm{L}$ was taken from each well and transferred to a fresh 96-well plate. The absorbance was measured at $\lambda=495 \mathrm{~nm}$ on a microplate reader (SpectraMax, Plus 384, Molecular Devices, Inc., USA). All the results were demonstrated as the optical density values minus the absorbance of blank wells.

2.5. Magnetic Heating Property of Magnetic Fe-MBG/C Composite Scaffolds. For the magnetic heating experiment, a high frequency generator with $5 \mathrm{KW}$ was used. The used inductor was a water-cooled copper coil with 11 turns on a length of $105 \mathrm{~mm}$ and a diameter of $42.5 \mathrm{~mm}$. For measurement, an open topped vessel with a dispersion of magnetic FeMBG/C particles grinded from the scaffolds $(150 \mathrm{mg} / \mathrm{mL})$ was placed in the inductor. Whilst application of the alternating magnetic field, the temperature was monitored using a pyrometer that was placed above the inductor and focused on the dispersion surface. To obtain the heating curve of the magnetic Fe-MBG/C scaffolds, a reference measurement of the pure solvent (equivalent volume) was subtracted from the data.

2.6. Loading and In Vitro Release of Ibuprofen. Ibuprofen (IBU, 99\%, Sigma-Aldrich) was used as a model drug to evaluate drug delivery property of magnetic Fe-MBG/C composites scaffolds in this study. Typically, $1.0 \mathrm{~g}$ of magnetic Fe-MBG scaffolds was immersed in $50 \mathrm{~mL}$ of IBU solution $(40 \mathrm{mg} / \mathrm{mL})$. After shaking on a shaking bed for $24 \mathrm{~h}$, the IBU-loaded Fe-MBG/C composite scaffolds were separated 


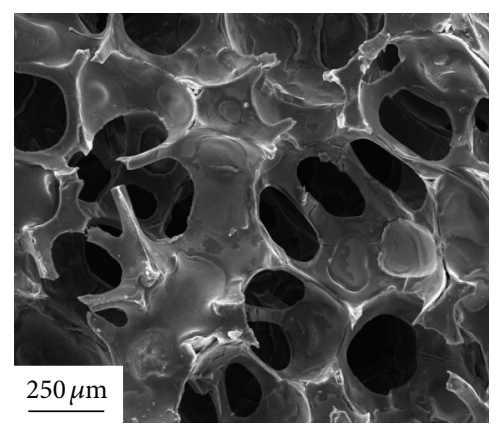

(a)

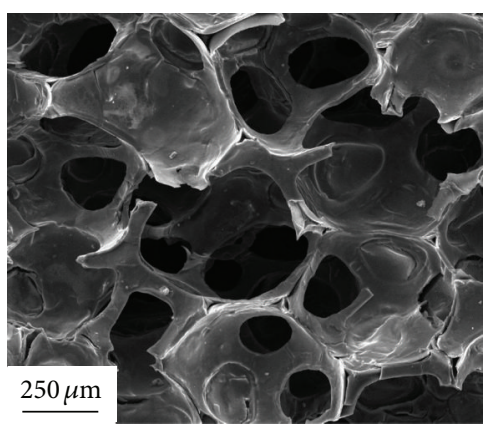

(b)

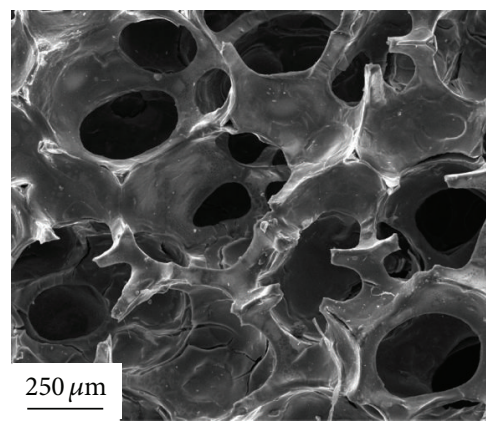

(c)

Figure 2: SEM images of the 0Fe-MBG/C (a), 5Fe-MBG/C (b), and 10Fe-MBG/C (c) composite scaffolds.

and dried in vacuum drying oven at $50^{\circ} \mathrm{C}$ for $48 \mathrm{~h}$. The estimation of IBU loading in magnetic Fe-MBG/C composite scaffolds was carried out by measuring the absorbance values at $264 \mathrm{~nm}$ before and after loading [8]. Before determination, a calibration curve was recorded by taking absorbance versus IBU concentration between 0 and $2 \mathrm{mg} / \mathrm{mL}$ as parameters.

In vitro release of IBU from the drug-loaded Fe-MBG/C scaffolds was following the previous reported method after some modification [8]. The IBU-loaded Fe-MBG/C scaffolds $(0.5 \mathrm{~g})$ were placed in a cover-sealed plastic bottle within $50 \mathrm{~mL}$ of SBF solution, and the plastic bottle was fixed on shaking bed with a 50 ramp of shaking speed at $37^{\circ} \mathrm{C}$. IBU release was determined by UV analysis. The release medium was withdrawn at the predetermined time intervals and replaced with fresh SBF solution each time. The extracted release medium was diluted with SBF and analyzed with a NanoDrop 2000C at the wavelength of $264 \mathrm{~nm}$.

\section{Results and Discussion}

SEM images of the Fe-MBG/C composite scaffolds with different Fe content are shown in Figure 2. All three Fe-MBG/C composite scaffolds exhibited a highly porous structure with a comparable interconnected macropore size, ranging from 200 to $500 \mu \mathrm{m}$. Using Archimedes' principle, the porosities of the open pores were $80.0 \pm 2.4 \%, 78.1 \pm 3.0 \%$, and 79.5 $\pm 0.8 \%$, for $0 \mathrm{Fe}-\mathrm{MBG} / \mathrm{C}$, $5 \mathrm{Fe}-\mathrm{MBG} / \mathrm{C}$, and $10 \mathrm{Fe}-\mathrm{MBG} / \mathrm{C}$ composite scaffolds, respectively. The results are similar to those of the previously reported MBG scaffolds [17-23], which suggested that the carbonization process could keep the interconnected macroporous structure of PU sponges. Previous studies demonstrated that the scaffold pores larger than $150 \mu \mathrm{m}$ and high porosity facilitated cells' proliferation, vascular ingrowth, and internal mineralized bone formation $[45,46]$. Therefore, from the viewpoint of porous structure, these prepared magnetic Fe-MBG/C composite scaffolds had suitable $3 \mathrm{D}$ macroporous structure for bone regeneration.

The WAXRD patterns of the Fe-MBG/C composite scaffolds with different Fe content are shown in Figure 3. A broad reflection at $2 \theta=15-30^{\circ}$ associated with amorphous carbon and silicate can be observed on all WAXRD patterns of the

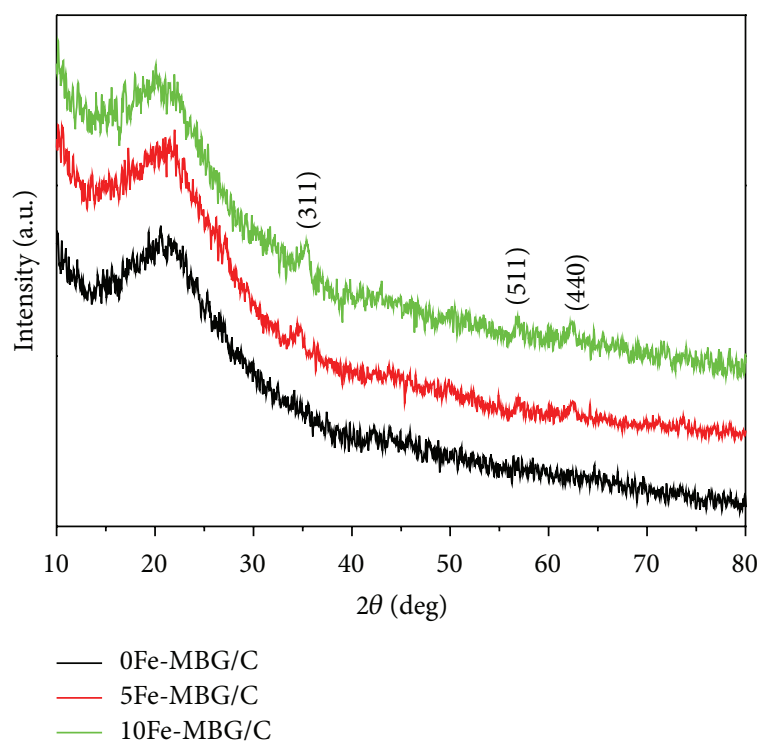

FIGURE 3: The WAXRD patterns of the Fe-MBG/C composite scaffolds with different Fe content.

Fe-MBG/C composite scaffolds. The 10Fe-MBG/C and 5FeMBG/C composite scaffolds exhibited weak and broad characteristic diffraction peaks of $\gamma-\mathrm{Fe}_{2} \mathrm{O}_{3}$ corresponding to the (311), (511), and (440) reflections, suggesting that very small $\gamma-\mathrm{Fe}_{2} \mathrm{O}_{3}$ nanocrystals have been formed in the Fe-MBG/C composite scaffolds. It might be attributed to the formation of $\gamma-\mathrm{Fe}_{2} \mathrm{O}_{3}$ from $\mathrm{Fe}^{3+}$ ions during the carbonization of the Fe-MBG/PU scaffolds. Generally, $\gamma-\mathrm{Fe}_{2} \mathrm{O}_{3}$ and $\mathrm{Fe}_{3} \mathrm{O}_{4}$ have the same spinel structure, and their XRD peak positions are quite close to each other. Previous studies demonstrated that $\mathrm{Fe}^{3+}$ ions in the polymeric frameworks could form $\gamma$ $\mathrm{Fe}_{2} \mathrm{O}_{3}$ nanocrystals, but not $\mathrm{Fe}_{3} \mathrm{O}_{4}$ nanocrystals, during the carbonization of the polymeric frameworks [47, 48].

Figure 4 shows TEM images of the Fe-MBG/C composite scaffolds with different Fe content. Each type of Fe-MBG/C composite scaffolds exhibited an ordered mesoporous structure, which was similar to those previously reported $\mathrm{MBG}$ powders and scaffolds $[3-10,17-25]$. However, the $\gamma-\mathrm{Fe}_{2} \mathrm{O}_{3}$ 


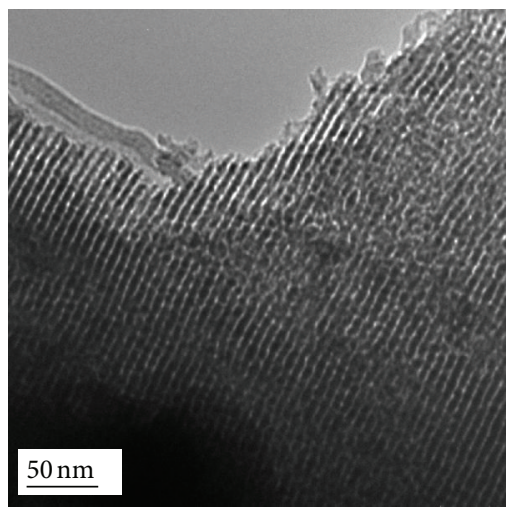

(a)

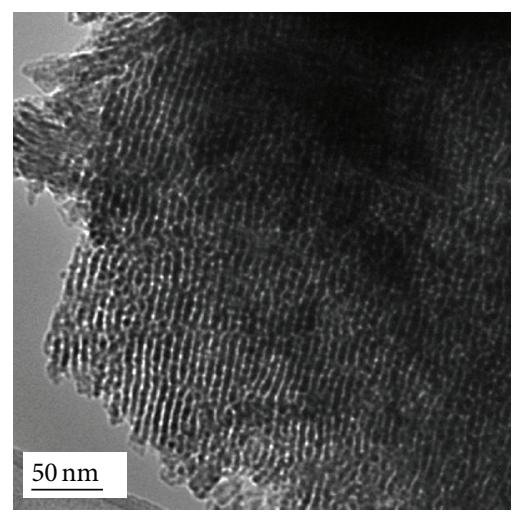

(b)

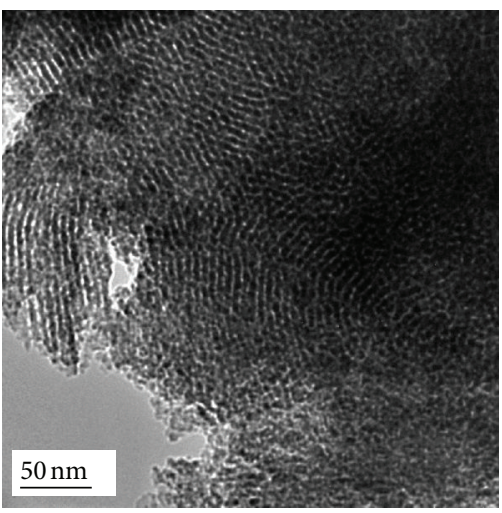

(c)

Figure 4: TEM images of the 0Fe-MBG/C (a), 5Fe-MBG/C (b), and 10Fe-MBG/C (c) composite scaffolds.

TABLE 2: Structural parameters and drug loading of the Fe-MBG/C and other MBG composite scaffolds.

\begin{tabular}{|c|c|c|c|c|c|c|c|}
\hline Samples & $\begin{array}{l}S_{\mathrm{BET}} \\
\left(\mathrm{m}^{2} / \mathrm{g}\right)\end{array}$ & $\begin{array}{c}V_{p} \\
\left(\mathrm{~cm}^{3} / \mathrm{g}\right)\end{array}$ & $\begin{array}{c}D_{p} \\
(\mathrm{~nm})\end{array}$ & $\begin{array}{c}\text { Porosity } \\
(\%)\end{array}$ & $\begin{array}{c}\text { Compressive } \\
\text { strength } \\
(\mathrm{kPa})\end{array}$ & $\begin{array}{c}\text { Drug loading } \\
(\%)\end{array}$ & References \\
\hline 0Fe-MBG/C & 254.4 & 0.248 & 4.4 & $80.0 \pm 2.4$ & $246.5 \pm 69.6$ & $16.2^{\mathrm{a}}$ & 1 \\
\hline 5Fe-MBG/C & 219.3 & 0.226 & 3.7 & $78.1 \pm 3.0$ & $284.9 \pm 25.5$ & $13.5^{\mathrm{a}}$ & 1 \\
\hline 10Fe-MBG/C & 189.7 & 0.189 & 3.9 & $79.5 \pm 0.8$ & $323.1 \pm 77.5$ & $12.6^{\mathrm{a}}$ & l \\
\hline MBG & 327.3 & 0.357 & 4.07 & 88.6 & $52.8 \pm 12.4$ & $11.3^{\mathrm{b}}$ & [24] \\
\hline 10Fe-MBG & 268 & 1 & 4.5 & $82.9 \pm 2.9$ & $46 \pm 5.4$ & $12.5^{\mathrm{c}}$ & {$[19]$} \\
\hline 5.0Silk-MBG & l & I & 5.0 & 94.0 & 250 & $15.7^{\mathrm{d}}$ & {$[26]$} \\
\hline $60 \% \mathrm{MBG} / \mathrm{PCL}$ & $505^{\mathrm{e}}$ & $0.5^{\mathrm{e}}$ & $5.4^{\mathrm{e}}$ & I & $9.3 \pm 3.9 \mathrm{MPa}^{\mathrm{f}}$ & I & {$[28]$} \\
\hline
\end{tabular}

${ }^{a}$ ibuprofen loading; ${ }^{b}$ gentamicin loading; ${ }^{c, d}$ dexamethasone loading; ${ }^{e}$ the surface area, pore volume, and pore size for MBG materials; ${ }^{\mathrm{f}} 3 \mathrm{D}$ rapid prototyping technique for the fabrication of MBG/PCL scaffolds.

nanoparticles or aggregates in the $5 \mathrm{Fe}-\mathrm{MBG} / \mathrm{C}$ and $10 \mathrm{Fe}$ MBG/C composite scaffolds cannot be clearly observed. It might be that the $\mathrm{Fe}^{3+}$ ions substituted the $\mathrm{Ca}^{2+}$ ions in the MBG framework during the sol-gel process and the carbonization under argon atmosphere but did not form the magnetic nanoparticles inside the channels, which are similar to the results reported by $\mathrm{Gu}$ et al. and Wu et al. $[49,50]$.

Figure 5 shows $\mathrm{N}_{2}$ adsorption-desorption isotherms of the magnetic Fe-MBG/C composite scaffolds together with the corresponding pore size distributions. The data of the surface area, pore volume, and pore size are listed in Table 2. As shown in Figure 5(a), these Fe-MBG/C composite scaffolds exhibited the type IV isotherms, indicating the mesoporous structure. However, the magnetic Fe-MBG/C composite scaffolds showed a decrease in the $\mathrm{N}_{2}$ adsorbed volume with the increase of $\mathrm{Fe}$ content, which suggested that the incorporation of $\gamma-\mathrm{Fe}_{2} \mathrm{O}_{3}$ could influence their BET surface area and pore volume. The specific surface areas of the $0 \mathrm{Fe}-$ MBG/C, 5Fe-MBG/C, and 10Fe-MBG/C composite scaffolds were $254.4,219.3$, and $189.7 \mathrm{~m}^{2} / \mathrm{g}$, respectively. The single point adsorption total volumes at $P / P_{0}=0.99$ were 0.248 , 0.226 , and $0.189 \mathrm{~cm}^{3} / \mathrm{g}$, respectively. It might be attributed to the decrease of the ordered degree of the magnetic Fe$\mathrm{MBG} / \mathrm{C}$ composite with increasing Fe content, because the substitution of $\mathrm{Fe}$ for $\mathrm{Ca}$ in the $\mathrm{Fe}-\mathrm{MBG} / \mathrm{C}$ scaffolds may cause a large number of defects in the mesoporous framework due to the difference of valence and atom diameter. The results were similar to those of the doped MBG materials [20-25, 51, 52]. The pore size distributions in Figure 5(b) were calculated from the adsorption branches using the $\mathrm{BJH}$ model. These magnetic Fe-MBG/C composite scaffolds exhibited relatively narrow pore size distributions, and the peak pore radii of the $0 \mathrm{Fe}-\mathrm{MBG} / \mathrm{C}, 5 \mathrm{Fe}-\mathrm{MBG} / \mathrm{C}$, and $10 \mathrm{Fe}-$ $\mathrm{MBG} / \mathrm{C}$ composite scaffolds were $2.20,1.85$, and $1.95 \mathrm{~nm}$, respectively. Therefore, these magnetic Fe-MBG/C composite scaffolds with high surface area, pore volume, and uniform mesoporous channels could be potential carriers for drug loading and delivery.

To determine the carbon content in the magnetic Fe-MBG/C composite scaffolds, thermogravimetric (TG) analysis was used in this study. As shown in Figure 6(a), each type of Fe-MBG/C composite scaffolds exhibited two weight losses. Weight losses below $200^{\circ} \mathrm{C}$ were the physical loss of water. Weight losses that occurred between 200 and $800^{\circ} \mathrm{C}$ were attributed to the carbon loss. Therefore, the carbon contents of the $0 \mathrm{Fe}-\mathrm{MBG} / \mathrm{C}, 5 \mathrm{Fe}-\mathrm{MBG} / \mathrm{C}$, and 10Fe-MBG/C composite scaffolds could be estimated to be 9.43, 9.89, and $11.54 \%$, respectively. As shown in Figure 6(b), 


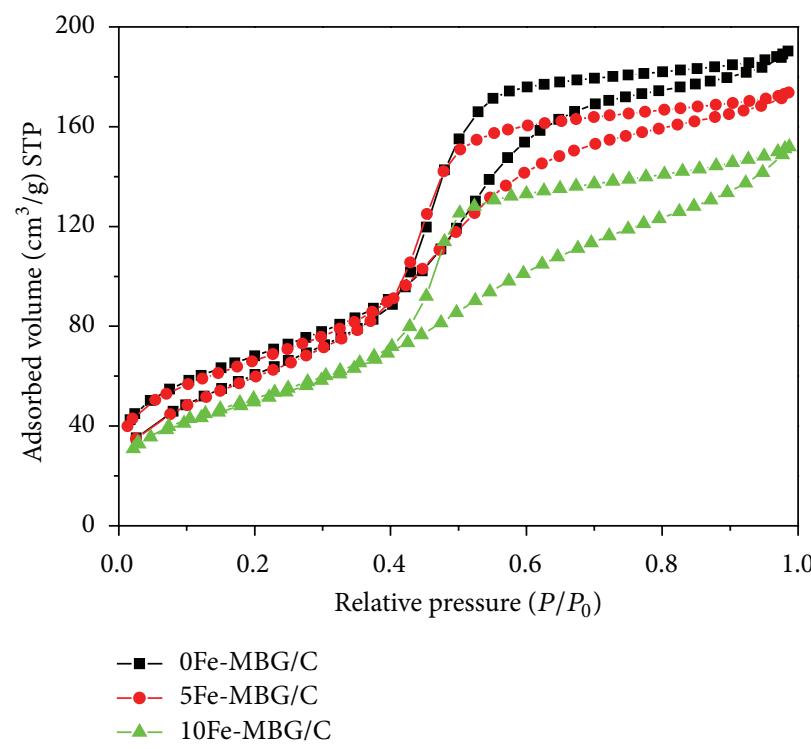

(a)

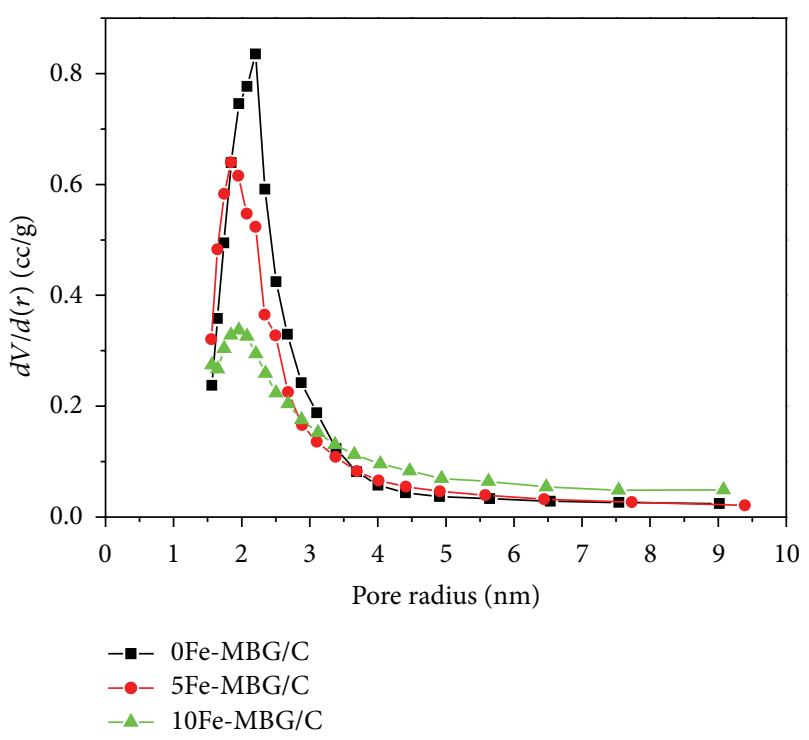

(b)

FIGURE 5: $\mathrm{N}_{2}$ adsorption isotherms (a) and the corresponding pore size distributions (b) of different Fe-MBG/C composite scaffolds.

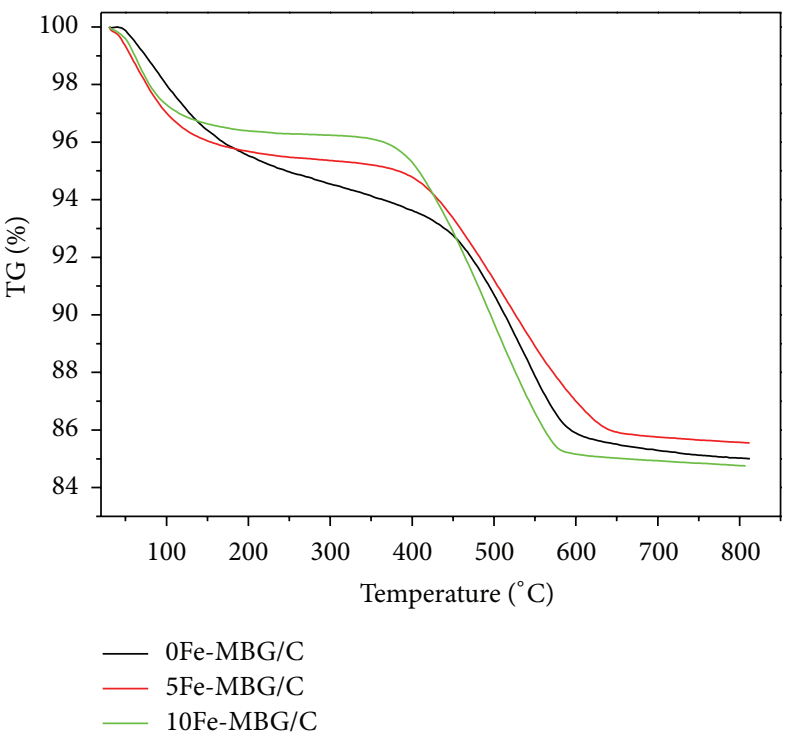

(a)

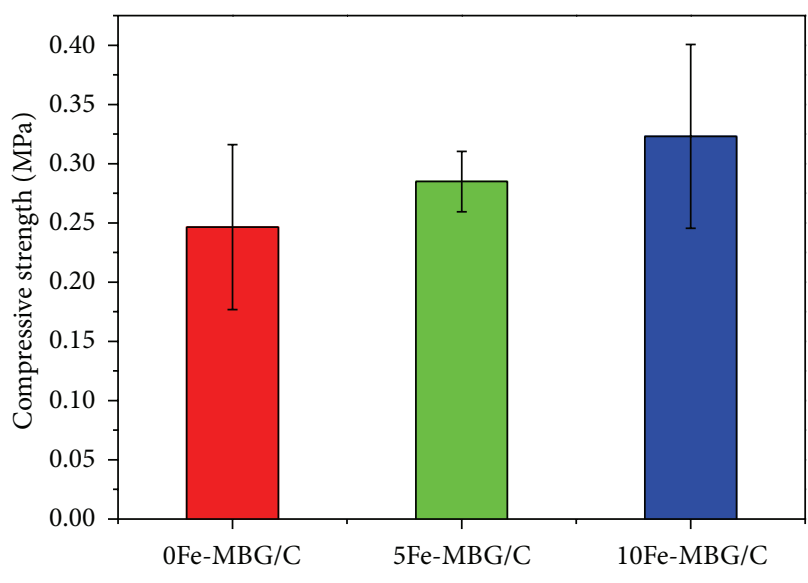

(b)

Figure 6: TG curves (a) and mechanical strength (b) of the Fe-MBG/C composite scaffolds with different Fe content.

the compressive strengths of the $0 \mathrm{Fe}-\mathrm{MBG} / \mathrm{C}, 5 \mathrm{Fe}-\mathrm{MBG} / \mathrm{C}$, and $10 \mathrm{Fe}-\mathrm{MBG} / \mathrm{C}$ composite scaffolds were, respectively, estimated to be $246 \pm 69.6,284 \pm 25.5$, and $323 \pm 77.5 \mathrm{KPa}$, which showed a significant enhancement in the compressive strength compared to the pure $\mathrm{MBG}$ and doped $\mathrm{MBG}$ scaffolds (ca. $55 \mathrm{kPa}$ ) [19-24], and were close to those of the silk modified MBG scaffolds (ca. $250 \mathrm{kPa}$ ) [26]. It might be that the carbon component played an important role in the enhancement of the mechanical strength for the Fe-MBG/C composite scaffolds. On the other hand, the Fe-substitution in the MBG network might also contribute to more stable network for the MBG scaffold, because $\mathrm{Fe}^{3+}$ ions provide more bonding to $\mathrm{Si}$ and $\mathrm{O}$ network than $\mathrm{Ca}^{2+}$ ions.

The room temperature magnetization curves of the $0 \mathrm{Fe}$ MBG/C, 5Fe-MBG/C, and 10Fe-MBG/C composite scaffolds are shown in Figure 7(a). The magnetization of the Fe$\mathrm{MBG} / \mathrm{C}$ composite scaffolds increased with increasing $\mathrm{Fe}$ content. The $0 \mathrm{Fe}-\mathrm{MBG} / \mathrm{C}$ composite scaffolds had no magnetization due to no magnetic component in the scaffolds. But the 5Fe-MBG/C and 10Fe-MBG/C composite scaffolds reached 0.73 and $1.32 \mathrm{emu} / \mathrm{g}$ at $25 \mathrm{~K} \mathrm{Oe}$, respectively. It also can be observed that there are almost no hysteresis 


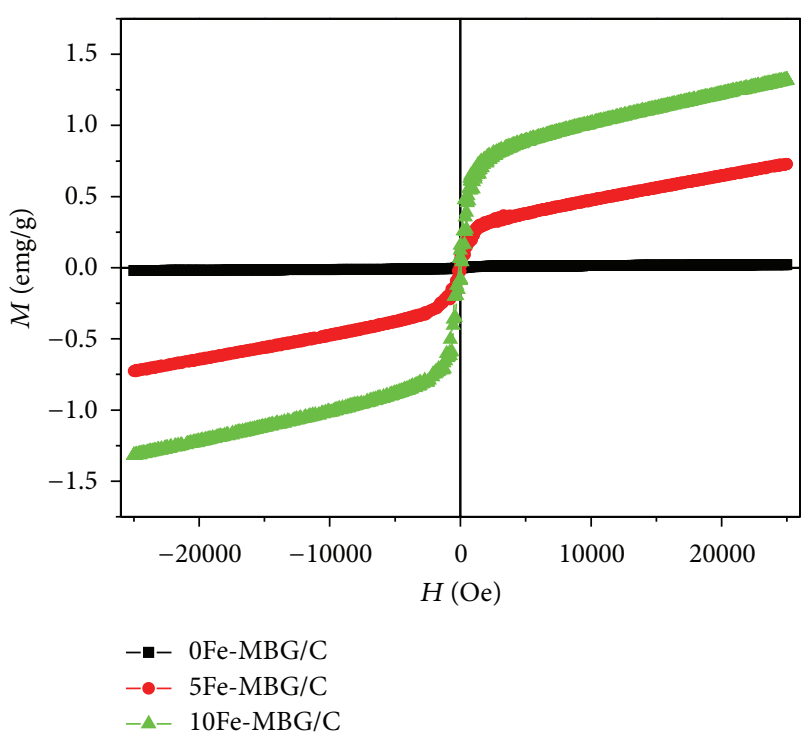

(a)

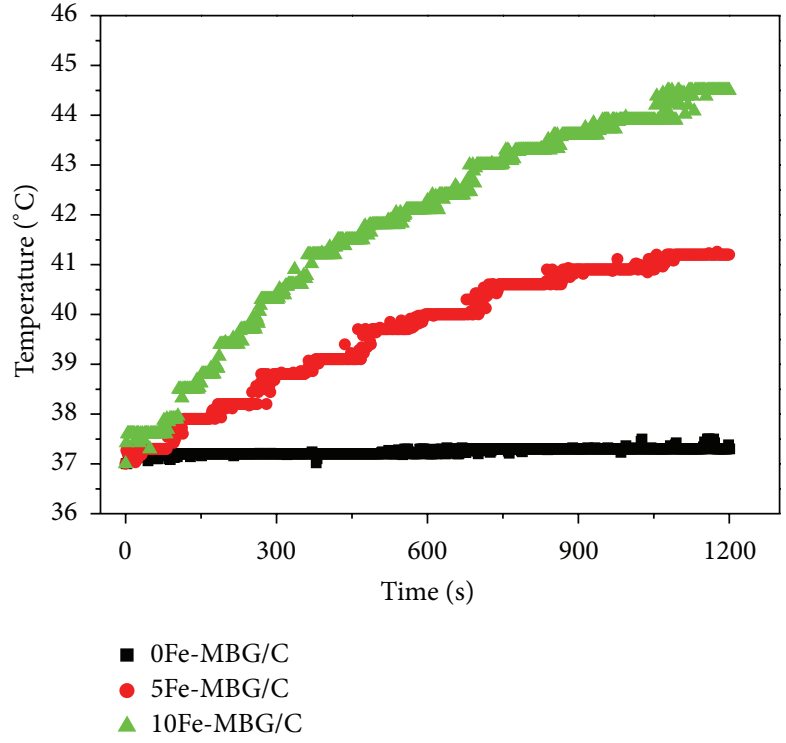

(b)

FIGURE 7: (a) Magnetization curves as a function of the applied magnetic field for different Fe-MBG/C composite scaffolds at room temperature; (b) magnetic heating curves of different Fe-MBG/C composite scaffolds in an alternating magnetic field.

loops (near-zero coercivity and remanence) for the $5 \mathrm{Fe}$ $\mathrm{MBG} / \mathrm{C}$ and 10Fe-MBG/C composite scaffolds, suggesting the superparamagnetic behavior of both $\mathrm{Fe}-\mathrm{MBG} / \mathrm{C}$ composite scaffolds because of the very small size of $\gamma$ - $\mathrm{Fe}_{2} \mathrm{O}_{3}$ crystals, which were restrained by the MBG framework.

Regarding the magnetic heating properties of the FeMBG/C composite scaffolds, Figure 7(b) shows the temperature increases of the Fe-MBG/C composite scaffolds in an alternating magnetic field whose magnetic field strength and frequency were $1.86 \mathrm{kA} / \mathrm{m}$ and $200 \mathrm{kHz}$, respectively. It can be observed that the temperature of the $0 \mathrm{Fe}-\mathrm{MBG} / \mathrm{C}$ suspension experienced minimal variation, starting at $37^{\circ} \mathrm{C}$ at the beginning of the magnetic field application and ending at $37.5^{\circ} \mathrm{C}$ after the observation period. However, the temperatures of the $5 \mathrm{Fe}-\mathrm{MBG} / \mathrm{C}$ and $10 \mathrm{Fe}-\mathrm{MBG} / \mathrm{C}$ suspensions increased from $37^{\circ} \mathrm{C}$ to 41.2 and $44.5^{\circ} \mathrm{C}$ after measuring $20 \mathrm{~min}$, respectively. The results indicated that the $5 \mathrm{Fe}-\mathrm{MBG} / \mathrm{C}$ and $10 \mathrm{Fe}-\mathrm{MBG} / \mathrm{C}$ composite scaffolds could generate heat to raise the temperature of the surrounding environment due to the delay in Neel relaxation of the magnetic moment in the composite scaffolds [53], allowing for magnetic hyperthermia application.

The bioactivity of the scaffold biomaterials is their ability to bond with living bone through the formation of an apatite layer on their surface both in vitro and in vivo [24]. Therefore, the apatite-forming ability is very important for magnetic Fe-MBG/C composite scaffolds. As shown in Figure 8, three Fe-MBG/C composite scaffolds had smooth surfaces before soaking in SBF solutions. However, it can be observed that a large amount of microparticles was deposited on the surfaces of three Fe-MBG/C composite scaffolds after soaking in SBF solutions for 3 days, which is similar to the previously reported formation of apatite particles on the MBG powders and scaffolds [3-7, 14-25]. The results indicated that the magnetic Fe-MBG/C composite scaffolds are bioactive according to Kokubo's view [44].

The cytotoxicities of three Fe-MBG/C composite scaffolds were evaluated by cell viability assay. As shown in Figure 9, there was no discernible cytotoxicity for three Fe-MBG/C composite scaffolds, by the fact that all experimental groups had close values to those of the controls. With the increase of culture time, the cell numbers significantly increased on the $\mathrm{Fe}-\mathrm{MBG} / \mathrm{C}$ composite scaffolds. It indicated that these magnetic Fe-MBG/C composite scaffolds were biocompatible, allowing cell attachment, proliferation, and differentiation, further determining the bone formation and bonding.

To understand the drug delivery property of these magnetic Fe-MBG/C composite scaffolds, ibuprofen (IBU), an analgesic and anti-inflammatory drug with molecular size of $\approx 1.0 \times 0.6 \mathrm{~nm}$, was used as a model drug to introduce into the mesopores of the Fe-MBG/C composite scaffolds [54, 55], which might be useful for bone tissue regeneration. IBU loading efficiency (mass of IBU/mass of scaffolds) of the $0 \mathrm{Fe}$ MBG/C, 5Fe-MBG/C, and 10Fe-MBG/C composite scaffolds was decreased with increasing Fe content and estimated to be $16.2 \%, 13.5 \%$, and $12.6 \%$, respectively (Table 2 ). Comparing the specific surface area, pore volume, and IBU loading efficiency of these Fe-MBG/C composite scaffolds, it can be suggested that the IBU loading efficiency was dependent on the specific surface area and pore volume of the scaffolds. The higher specific surface area and pore volume resulted in the higher loading efficiency. The release tests were performed in SBF solutions. As shown in Figure 10, three Fe-MBG/C composite scaffolds exhibited a similar sustained release behavior during the whole test period. The incorporation of $\gamma-\mathrm{Fe}_{2} \mathrm{O}_{3}$ into the MBG/C scaffolds did not change the 


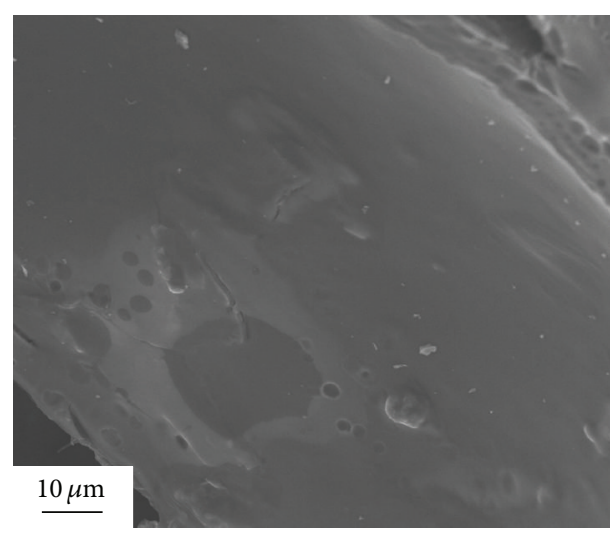

(a)

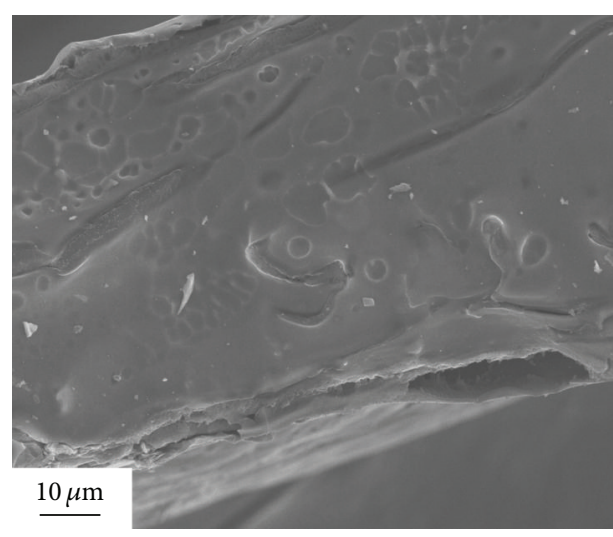

(c)

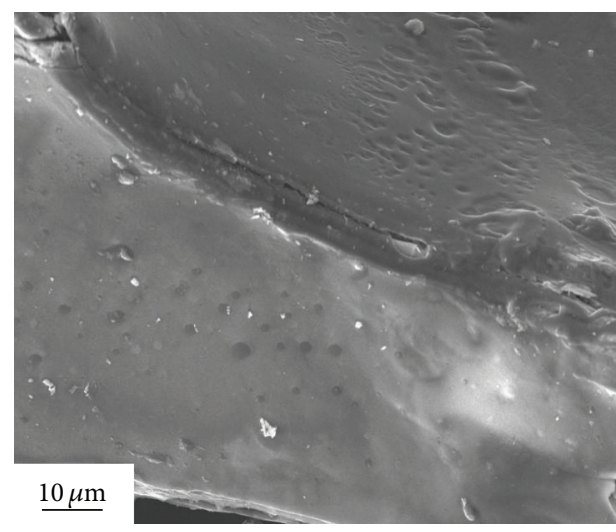

(e)

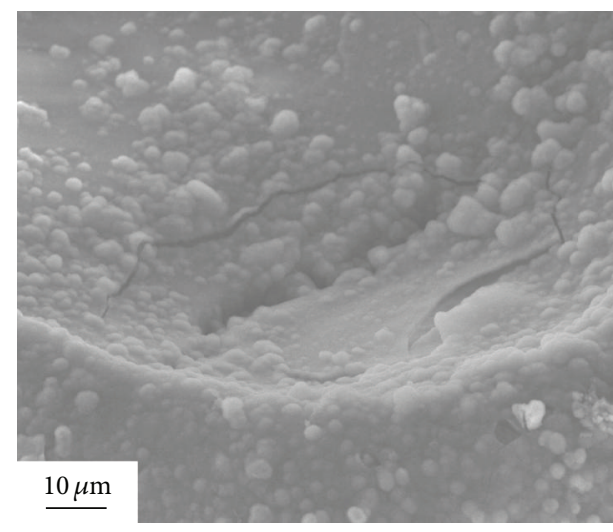

(b)

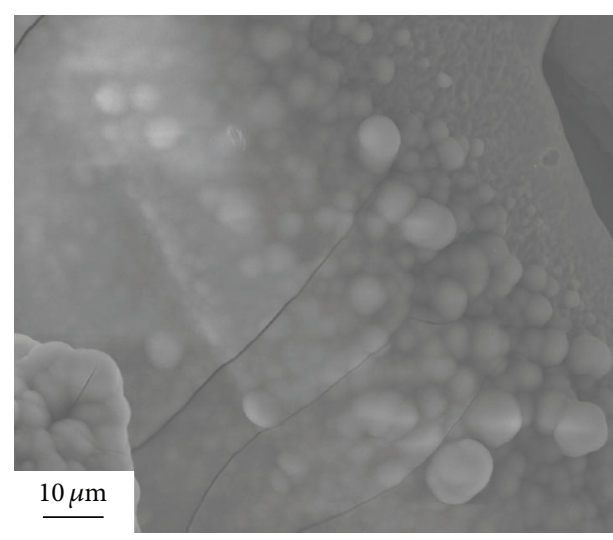

(d)

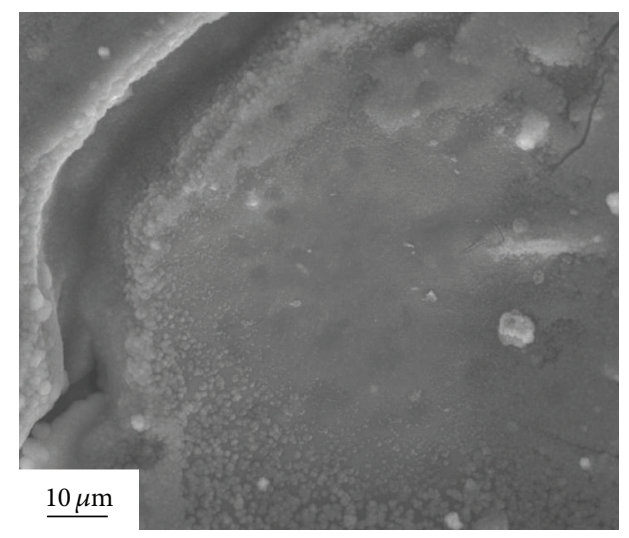

(f)

FIGURE 8: SEM images of the Fe-MBG/C composite scaffolds before ( $a, c$, and e) and after (b, $d$, and $f$ ) soaking in SBF solutions for 3 days ((a) and (b) for the 0Fe-MBG/C scaffolds; (c) and (d) for the 5Fe-MBG/C scaffolds; (e) and (f) for the 10Fe-MBG/C scaffolds).

release kinetics of IBU, an initial fast release followed by a relatively slow release with increasing the release time. It is similar to those previously reported sustained drug release systems based on mesoporous silica and MBG materials due to the presence of mesoporous channels [8-10, 56, 57]. However, the release rates from these magnetic Fe-MBG/C composite scaffolds exhibited a little decrease with increasing Fe content, which is similar to the previously reported IBU release from the $\mathrm{Fe}_{3} \mathrm{O}_{4}-\mathrm{CaO}-\mathrm{SiO}_{2}-\mathrm{P}_{2} \mathrm{O}_{5} \mathrm{MBG}$ composites by $\mathrm{Li}$ et al. [8]. Generally, the drug release from mesoporous materials dominated by Fickian diffusion mechanism was dependent on the mesoporous structure, mesopore size, surface chemistry, and the release environment. In this study, the $0 \mathrm{Fe}-\mathrm{MBG} / \mathrm{C}, 5 \mathrm{Fe}-\mathrm{MBG} / \mathrm{C}$, and $10 \mathrm{Fe}-\mathrm{MBG} / \mathrm{C}$ composite scaffolds had similar mesoporous structure, mesopore size, and surface chemistry. However, the ion dissolution rate of the Fe-MBG/C composite scaffolds decreased with increasing the Fe substitution due to the easier dissolution of Ca species than that of Fe species in SBF solution [8]. Therefore, the limited control of drug release was due to the limited change 


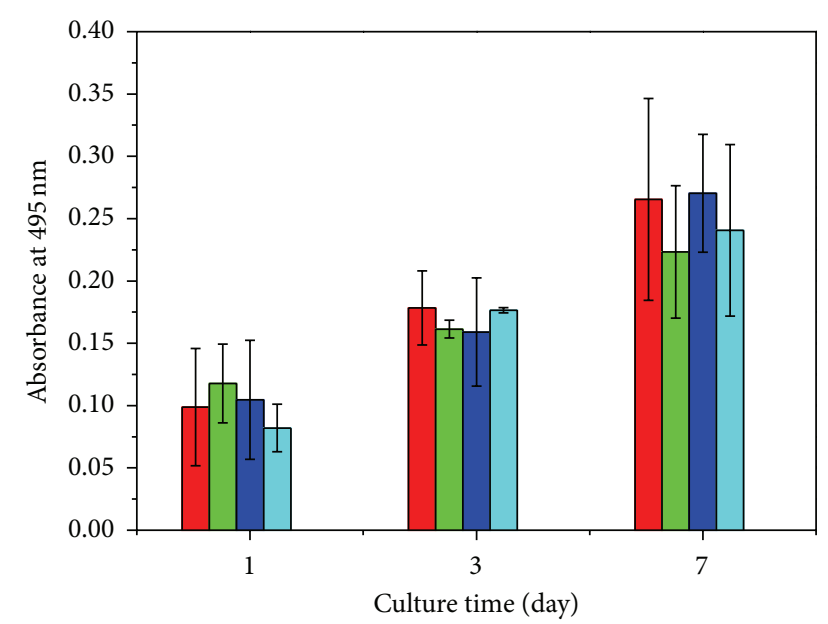

$\begin{array}{ll}\text { Control } & \text { 5Fe-MBG/C } \\ \text { 0Fe-MBG/C } & \square \text { 10Fe-MBG/C }\end{array}$

Figure 9: The cytotoxicities of the Fe-MBG/C composite scaffolds evaluated by MTT assay.

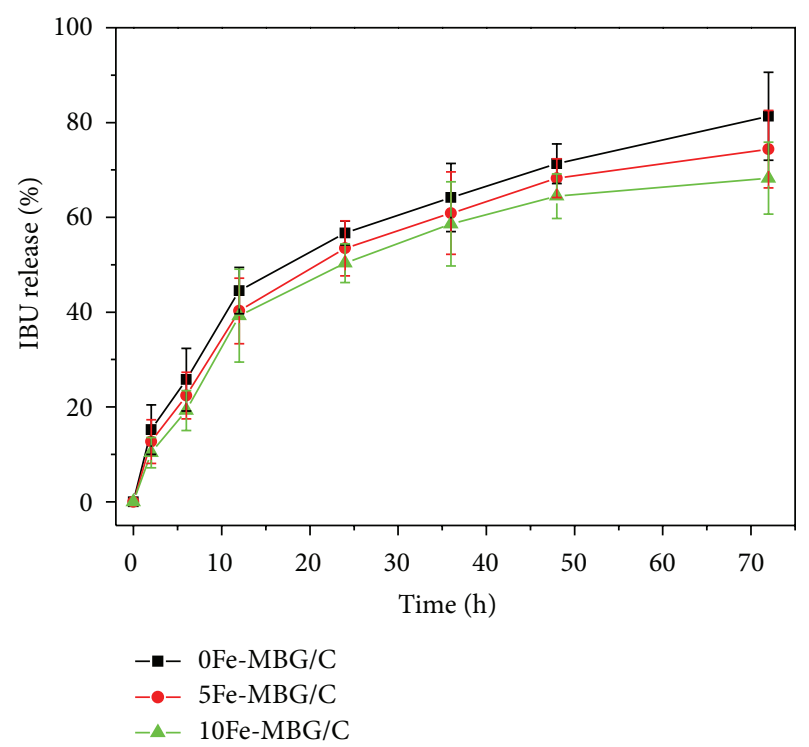

FIGURE 10: Ibuprofen release profiles from the Fe-MBG/C composite scaffolds with different Fe content.

of the ion dissolution rate of different Fe-MBG/C composite scaffolds during the release period. Wu et al. also reported that the faster dissolution rate of mesoporous $\mathrm{SrO}-\mathrm{SiO}_{2}$ particles contributed to the faster rate of dexamethasone (DEX) release [58]. Therefore, these magnetic Fe-MBG/C composite scaffolds have potential as a local sustained drug delivery system for bone regeneration.

\section{Conclusions}

The magnetic Fe-MBG/C composite scaffolds with enhanced mechanical strength and multifunctionality have been successfully prepared. The Fe-MBG/C composite scaffolds had interconnected macropores of $200-500 \mu \mathrm{m}$ and mesoporous walls with mesopores of ca. 3.7-4.4 $\mathrm{nm}$ and enhanced the compressive strength with four times compared to the MBG scaffolds with similar porosity due to the reinforcement of carbon component. The Fe-MBG/C composite scaffolds exhibited good bioactivity and sustained drug release property. Importantly, the Fe-MBG/C composite scaffolds were superparamagnetic and could generate heat in an alternating magnetic field for potential hyperthermia application. Therefore, the magnetic Fe-MBG/C composite scaffolds have potential for the regeneration of the critical-sized bone defects caused by bone tumors by a combination of magnetic hyperthermia and local drug delivery.

\section{Acknowledgments}

The authors gratefully acknowledge the support by the Program for Professor of Special Appointment (Eastern Scholar) at Shanghai Institutions of Higher Learning, National Natural Science Foundation of China (no. 51102166), Program for New Century Excellent Talent in University (no. NCET12-1053), Key Project of Chinese Ministry of Education (no. 212055), Shanghai Pujiang Program (no. 11PJ1407300), Shanghai Shuguang Project (no. 12SG39), and Innovation Program of Shanghai Municipal Education Commission (no. 12ZZ140).

\section{References}

[1] M. Vallet-Regí, M. Colilla, and I. Izquierdo-Barba, "Bioactive mesoporous silicas as controlled delivery systems: application in bone tissue regeneration," Journal of Biomedical Nanotechnology, vol. 4, no. 1, pp. 1-15, 2008.

[2] C. Wu, J. Chang, and Y. Xiao, "Mesoporous bioactive glasses as drug delivery and bone tissue regeneration platforms," Therapeutic Delivery, vol. 2, no. 9, pp. 1189-1198, 2011.

[3] X. Yan, C. Yu, X. Zhou, J. Tang, and D. Zhao, "Highly ordered mesoporous bioactive glasses with superior in vitro bone-forming bioactivities," Angewandte Chemie - International Edition, vol. 43, no. 44, pp. 5980-5984, 2004.

[4] A. López-Noriega, D. Arcos, I. Izquierdo-Barba, Y. Sakamoto, O. Terasaki, and M. Vallet-Regí, "Ordered mesoporous bioactive glasses for bone tissue regeneration," Chemistry of Materials, vol. 18, no. 13, pp. 3137-3144, 2006.

[5] Y. Hong, X. Chen, X. Jing, H. Fan, Z. Gu, and X. Zhang, "Fabrication and drug delivery of ultrathin mesoporous bioactive glass hollow fibers," Advanced Functional Materials, vol. 20, no. 9, pp. 1503-1510, 2010.

[6] F. Baino, S. Fiorilli, R. Mortera et al., "Mesoporous bioactive glass as a multifunctional system for bone regeneration and controlled drug release," Journal of Applied Biomaterials \& Functional Materials, vol. 10, pp. 12-21, 2012.

[7] J. Zhang, F. Y. Qu, H. M. Lin, X. Wu, and J. J. Jiang, "Mesoporous bioactive glass: ideal material for higher uptake and well sustained release of ibuprofen," Materials Research Innovations, vol. 16, pp. 230-235, 2012.

[8] X. Li, X. Wang, Z. Hua, and J. Shi, "One-pot synthesis of magnetic and mesoporous bioactive glass composites and their sustained drug release property," Acta Materialia, vol. 56, no. 13, pp. 3260-3265, 2008. 
[9] W. Xia and J. Chang, "Well-ordered mesoporous bioactive glasses (MBG): a promising bioactive drug delivery system," Journal of Controlled Release, vol. 110, no. 3, pp. 522-530, 2006.

[10] L. Zhao, X. Yan, X. Zhou et al., "Mesoporous bioactive glasses for controlled drug release," Microporous and Mesoporous Materials, vol. 109, no. 1-3, pp. 210-215, 2008.

[11] G. M. Calori, E. Mazza, M. Colombo, and C. Ripamonti, “The use of bone-graft substitutes in large bone defects: any specific needs?" Injury, vol. 42, 2, pp. S56-S63, 2011.

[12] Y.-S. Park, K.-N. Kim, K.-M. Kim et al., "Feasibility of threedimensional macroporous scaffold using calcium phosphate glass and polyurethane sponge," Journal of Materials Science, vol. 41, no. 13, pp. 4357-4364, 2006.

[13] M. De Barros Coelho and M. Magalhães Pereira, "Sol-gel synthesis of bioactive glass scaffolds for tissue engineering: effect of surfactant type and concentration," Journal of Biomedical Materials Research - Part B Applied Biomaterials, vol. 75, no. 2, pp. 451-456, 2005.

[14] H.-S. Yun, S.-E. Kim, and Y.-T. Hyeon, "Design and preparation of bioactive glasses with hierarchical pore networks," Chemical Communications, no. 21, pp. 2139-2141, 2007.

[15] H.-S. Yun, S.-E. Kim, Y.-T. Hyun, S.-J. Heo, and J.-W. Shin, "Hierarchically mesoporous-macroporous bioactive glasses scaffolds for bone tissue regeneration," Journal of Biomedical Materials Research B, vol. 87, no. 2, pp. 374-380, 2008.

[16] H. Lin, J. Ma, X. Li, X. Wu, and F. Qu, "A co-templated approach to hierarchically mesoporous-macroporous bioactive glasses (MMBG) scaffolds for bone tissue regeneration," Journal of SolGel Science and Technology, vol. 62, pp. 170-176, 2012.

[17] Y. Zhu, C. Wu, Y. Ramaswamy et al., "Preparation, characterization and in vitro bioactivity of mesoporous bioactive glasses (MBGs) scaffolds for bone tissue engineering," Microporous and Mesoporous Materials, vol. 112, no. 1-3, pp. 494-503, 2008.

[18] Y. Zhu and S. Kaskel, "Comparison of the in vitro bioactivity and drug release property of mesoporous bioactive glasses (MBGs) and bioactive glasses (BGs) scaffolds," Microporous and Mesoporous Materials, vol. 118, no. 1-3, pp. 176-182, 2009.

[19] C. Wu, W. Fan, Y. Zhu et al., "Multifunctional magnetic mesoporous bioactive glass scaffolds with a hierarchical pore structure," Acta Biomaterialia, vol. 7, no. 10, pp. 3563-3572, 2011.

[20] C. Wu, R. Miron, A. Sculean et al., "Proliferation, differentiation and gene expression of osteoblasts in boron-containing associated with dexamethasone deliver from mesoporous bioactive glass scaffolds," Biomaterials, vol. 32, no. 29, pp. 7068-7078, 2011.

[21] C. Wu, Y. Zhou, C. Lin, J. Chang, and Y. Xiao, "Strontiumcontaining mesoporous bioactive glass scaffolds with improved osteogenic/cementogenic differentiation of periodontal ligament cells for periodontal tissue engineering," Acta Biomaterialia, vol. 8, pp. 3805-3815, 2012.

[22] C. Wu, Y. Zhou, M. Xu et al., "Copper-containing mesoporous bioactive glass scaffolds with multifunctional properties of angiogenesis capacity, osteostimulation and antibacterial activity," Biomaterials, vol. 34, pp. 422-433, 2013.

[23] C. Wu, Y. Zhou, W. Fan et al., "Hypoxia-mimicking mesoporous bioactive glass scaffolds with controllable cobalt ion release for bone tissue engineering," Biomaterials, vol. 33, no. 7, pp. 20762085, 2012.

[24] Y. Zhu, X. Li, J. Yang, S. Wang, H. Gao, and N. Hanagata, "Composition-structure-property relationships of the CaO$\mathrm{M}_{x} \mathrm{O}_{y}-\mathrm{SiO}_{2}-\mathrm{P}_{2} \mathrm{O}_{5}(\mathrm{M}=\mathrm{Zr}, \mathrm{Mg}, \mathrm{Sr})$ mesoporous bioactive glass (MBG) scaffolds," Journal of Materials Chemistry, vol. 21, no. 25, pp. 9208-9218, 2011.
[25] X. Wang, X. Li, A. Ito, and Y. Sogo, "Synthesis and characterization of hierarchically macroporous and mesoporous $\mathrm{CaO}$ MO- $\mathrm{SiO}_{2}-\mathrm{P}_{2} \mathrm{O}_{5}(\mathrm{M}=\mathrm{Mg}, \mathrm{Zn}, \mathrm{Sr})$ bioactive glass scaffolds," Acta Biomaterialia, vol. 7, no. 10, pp. 3638-3644, 2011.

[26] C. Wu, Y. Zhang, Y. Zhu, T. Friis, and Y. Xiao, "Structureproperty relationships of silk-modified mesoporous bioglass scaffolds," Biomaterials, vol. 31, no. 13, pp. 3429-3438, 2010.

[27] Y. Zhu, Y. Zhang, C. Wu, Y. Fang, J. Yang, and S. Wang, “The effect of zirconium incorporation on the physiochemical and biological properties of mesoporous bioactive glasses scaffolds," Microporous and Mesoporous Materials, vol. 143, no. 2-3, pp. 311319, 2011.

[28] H.-S. Yun, S.-E. Kim, Y.-T. Hyun, S.-J. Heo, and J.-W. Shin, "Three-dimensional mesoporous - Giantporous inorganic/organic composite scaffolds for tissue engineering," Chemistry of Materials, vol. 19, no. 26, pp. 6363-6366, 2007.

[29] X. Li, J. Shi, X. Dong, L. Zhang, and H. Zeng, "A mesoporous bioactive glass/polycaprolactone composite scaffold and its bioactivity behavior," Journal of Biomedical Materials Research A, vol. 84, no. 1, pp. 84-91, 2008.

[30] J. Su, L. Cao, B. Yu et al., "Composite scaffolds of mesoporous bioactive glass and polyamide for bone repair," International Journal of Nanomedicine, vol. 7, pp. 2547-2555, 2012.

[31] S.-Z. Xue, H.-L. Zhu, J.-Y. Chen, X.-X. Feng, and J. Chang, "Preparation and properties of mesoporous bioactive glass/demineralized bone composite scaffolds," Journal of Inorganic Materials, vol. 26, no. 10, pp. 1068-1072, 2011.

[32] W. Xu, "Biocompatibility and medical application of carbon material," Key Engineering Materials, vol. 452-453, pp. 477-480, 2011.

[33] X. Hou, Q. Chen, C. Yu, and J. Shen, "Biocompatibility and medical application of carbon-carbon composites," Advanced Functional Materials, vol. 31, pp. 460-463, 2000.

[34] D. Lahiri, S. Ghosh, and A. Agarwal, "Carbon nanotube reinforced hydroxyapatite composite for orthopedic application: a review," Materials Science and Engineering C, vol. 32, pp. 17271758, 2012.

[35] A. R. Boccaccini, F. Chicatun, J. Cho et al., "Carbon nanotube coatings on bioglass-based tissue engineering scaffolds," Advanced Functional Materials, vol. 17, no. 15, pp. 2815-2822, 2007.

[36] G. Li, S. Feng, and D. Zhou, "Magnetic bioactive glass ceramic in the system $\mathrm{CaO}-\mathrm{P}_{2} \mathrm{O}_{5}-\mathrm{SiO}_{2}-\mathrm{MgO}-\mathrm{CaF}_{2}-\mathrm{MnO}_{2}-\mathrm{Fe}_{2} \mathrm{O}_{3}$ for hyperthermia treatment of bone tumor," Journal of Materials Science, vol. 22, no. 10, pp. 2197-2206, 2011.

[37] X. B. Zeng, H. Hu, L. Q. Xie et al., "Magnetic responsive hydroxyapatite composite scaffolds construction for bone defect reparation," International Journal of Nanomedicine, vol. 7, pp. 33653378, 2012.

[38] F. M. Martín-Saavedra, E. Ruíz-Hernández, A. Boré, D. Arcos, M. Vallet-Regí, and N. Vilaboa, "Magnetic mesoporous silica spheres for hyperthermia therapy," Acta Biomaterialia, vol. 6, no. 12, pp. 4522-4531, 2010.

[39] M. C. Serrano, M. T. Portolés, R. Pagani et al., "In vitro positive biocompatibility evaluation of glass-glass ceramic thermoseeds for hyperthermic treatment of bone tumors," Tissue Engineering A, vol. 14 , no. 5, pp. 617-627, 2008.

[40] M. Kawashita, K. Kawamura, and Z. Li, "PMMA-based bone cements containing magnetite particles for the hyperthermia of cancer," Acta Biomaterialia, vol. 6, no. 8, pp. 3187-3192, 2010. 
[41] S. Murakami, T. Hosono, B. Jeyadevan, M. Kamitakahara, and $\mathrm{K}$. Ioku, "Hydrothermal synthesis of magnetite/hydroxyapatite composite material for hyperthermia therapy for bone cancer," Journal of the Ceramic Society of Japan, vol. 116, no. 1357, pp. 950954, 2008.

[42] M. Kawashita, Y. Iwahashi, T. Kokubo, T. Yao, S. Hamada, and T. Shinjo, "Preparation of glass-ceramics containing ferrimagnetic zinc-iron ferrite for the hyperthermal treatment of cancer," Journal of the Ceramic Society of Japan, vol. 112, no. 1307, pp. 373-379, 2004.

[43] Y. Zhu, F. Shang, B. Li et al., "Magnetic mesoporous bioactive glass scaffolds: preparation, physicochemistry and biological properties," Journal of Materials Chemistry B, vol. 1, pp. 12791288, 2013.

[44] T. Kokubo and H. Takadama, "How useful is SBF in predicting in vivo bone bioactivity?" Biomaterials, vol. 27, no. 15, pp. 29072915, 2006.

[45] J. R. Jones and L. L. Hench, "Factors affecting the structure and properties of bioactive foam scaffolds for tissue engineering," Journal of Biomedical Materials Research B, vol. 68, no. 1, pp. 36-44, 2004.

[46] J. R. Jones and L. L. Hench, "Effect of surfactant concentration and composition on the structure and properties of sol-gelderived bioactive glass foam scaffolds for tissue engineering," Journal of Materials Science, vol. 38, no. 18, pp. 3783-3790, 2003.

[47] X. Dong, H. Chen, W. Zhao, X. Li, and J. Shi, "Synthesis and magnetic properties of mesostructured $\gamma-\mathrm{Fe}_{2} \mathrm{O}_{3} /$ carbon composites by a co-casting method," Chemistry of Materials, vol. 19, no. 14, pp. 3484-3490, 2007.

[48] Y. Zhu, L. Zhang, F. M. Schappacher, R. Pöttgen, J. Shi, and S. Kaskel, "Synthesis of magnetically separable porous carbon microspheres and their adsorption properties of phenol and nitrobenzene from aqueous solution," Journal of Physical Chemistry C, vol. 112, no. 23, pp. 8623-8628, 2008.

[49] J. L. Gu, X. Dong, S. P. Elangovan et al., "Simultaneous pore enlargement and introduction of highly dispersed Fe active sites in MSNs for enhanced catalytic activity," Journal of Solid State Chemistry, vol. 186, pp. 208-216, 2012.

[50] C. Wu, W. Fan, Y. Zhu et al., "Multifunctional magnetic mesoporous bioactive glass scaffolds with a hierarchical pore structure," Acta Biomaterialia, vol. 7, no. 10, pp. 3563-3572, 2011.

[51] S. Shruti, A. J. Salinas, G. Lusvardi, G. Malavasi, L. Menabue, and M. Vallet-Regi, "Mesoporous bioactive scaffolds prepared with cerium-, gallium-, and zinc-containing glass," Acta Biomaterialia, vol. 9, pp. 4836-4844, 2013.

[52] A. J. Salinas, S. Shruti, G. Malavasi, L. Menabue, and M. ValletRegí, "Substitutions of cerium, gallium and zinc in ordered mesoporous bioactive glasses," Acta Biomaterialia, vol. 7, no. 9, pp. 3452-3458, 2011.

[53] C. S. S. R. Kumar and F. Mohammad, "Magnetic nanomaterials for hyperthermia-based therapy and controlled drug delivery," Advanced Drug Delivery Reviews, vol. 63, no. 9, pp. 789-808, 2011.

[54] J. Zhang, F. Y. Qu, H. M. Lin, X. Wu, and J. J. Jiang, "Mesoporous bioactive glass: ideal materials for higher uptake and well sustained release of ibuprofen," Mater. Res. Innovations, vol. 16, pp. 230-235, 2012.

[55] M. Vallet-Regi, A. Rámila, R. P. Del Real, and J. Pérez-Pariente, "A new property of MCM-41: drug delivery system," Chemistry of Materials, vol. 13, no. 2, pp. 308-311, 2001.
[56] M. Vallet-Regi, A. Rámila, R. P. Del Real, and J. Pérez-Pariente, "A new property of MCM-41: drug delivery system," Chemistry of Materials, vol. 13, no. 2, pp. 308-311, 2001.

[57] Y. Zhu, J. Shi, W. Shen, H. Chen, X. Dong, and M. Ruan, "Preparation of novel hollow mesoporous silica spheres and their sustained-release property," Nanotechnology, vol.16, no. 11, pp. 2633-2638, 2005.

[58] C. Wu, W. Fan, M. Gelinsky et al., "Bioactive $\mathrm{SrO}-\mathrm{SiO}_{2}$ glass with well-ordered mesopores: characterization, physiochemistry and biological properties," Acta Biomaterialia, vol. 7, no. 4, pp. 1797-1806, 2011. 

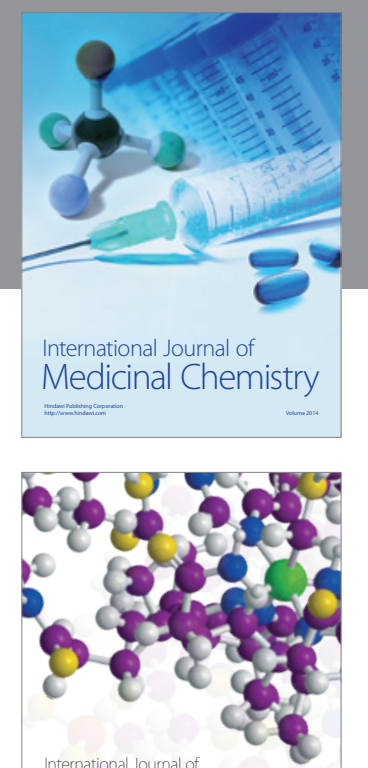

\section{Carbohydrate} Chemistry

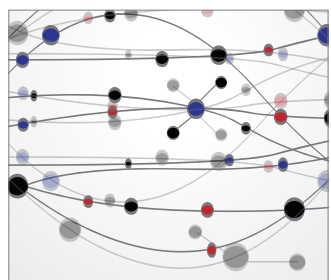

The Scientific World Journal
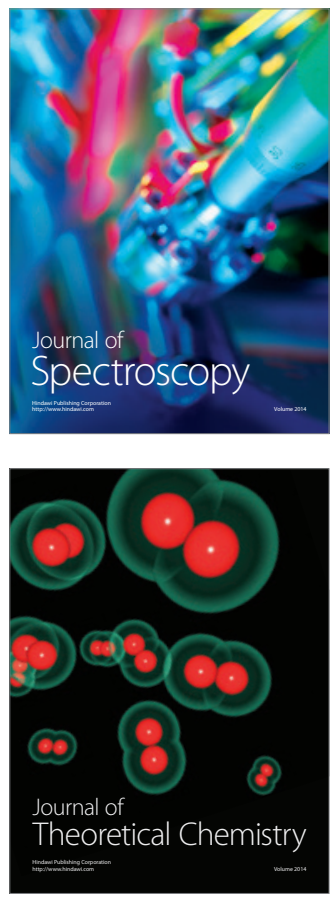
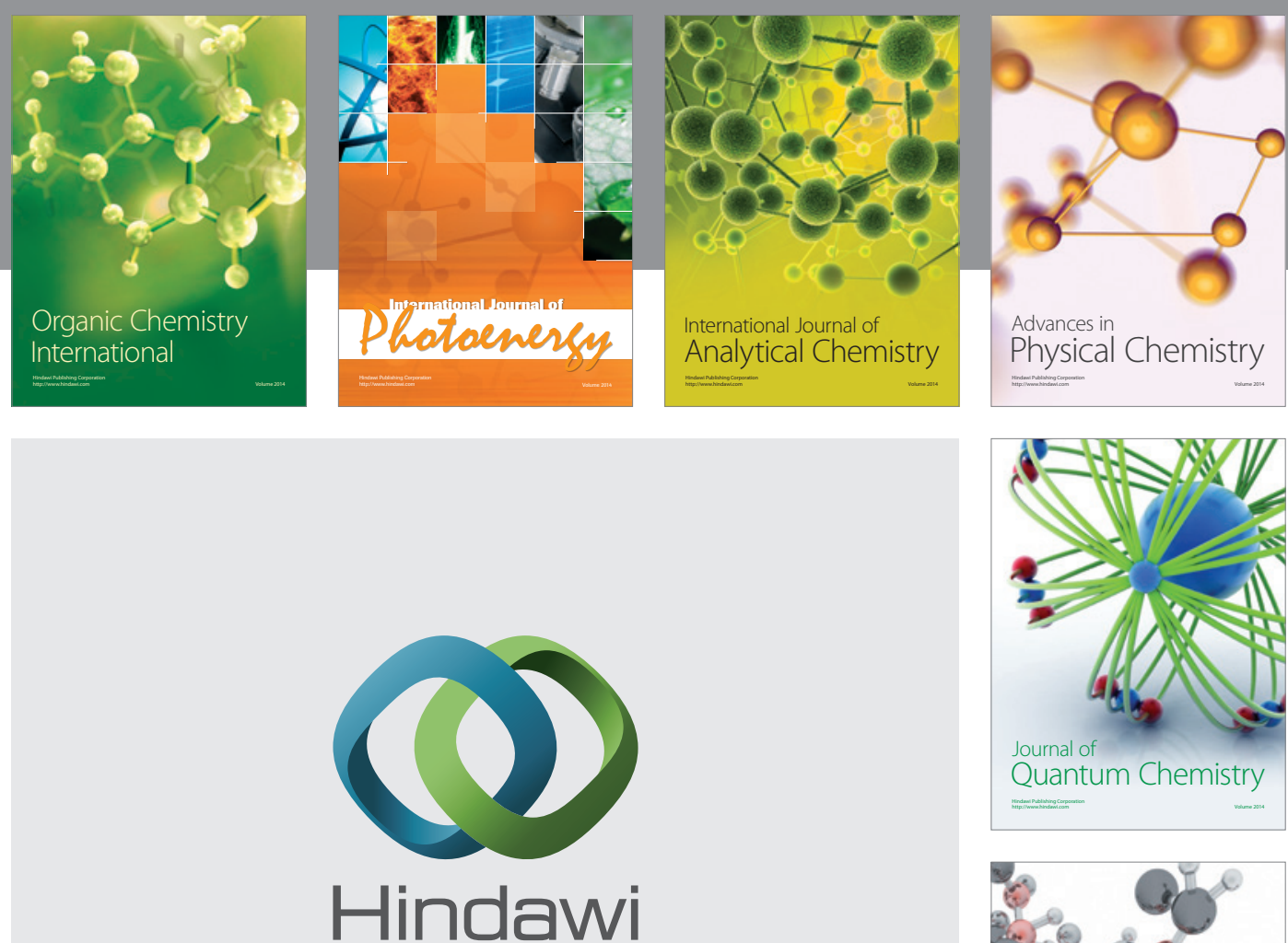

Submit your manuscripts at

http://www.hindawi.com

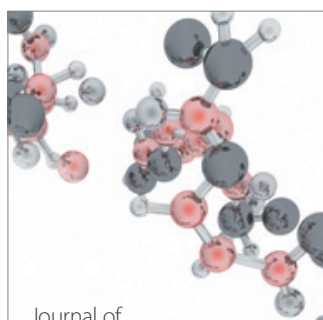

Analytical Methods

in Chemistry

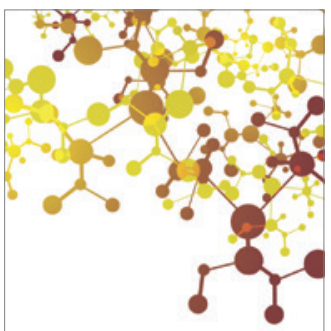

Journal of

Applied Chemistry

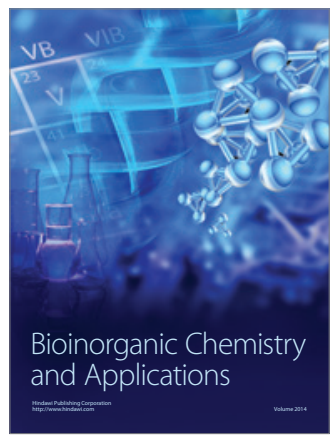

Inorganic Chemistry
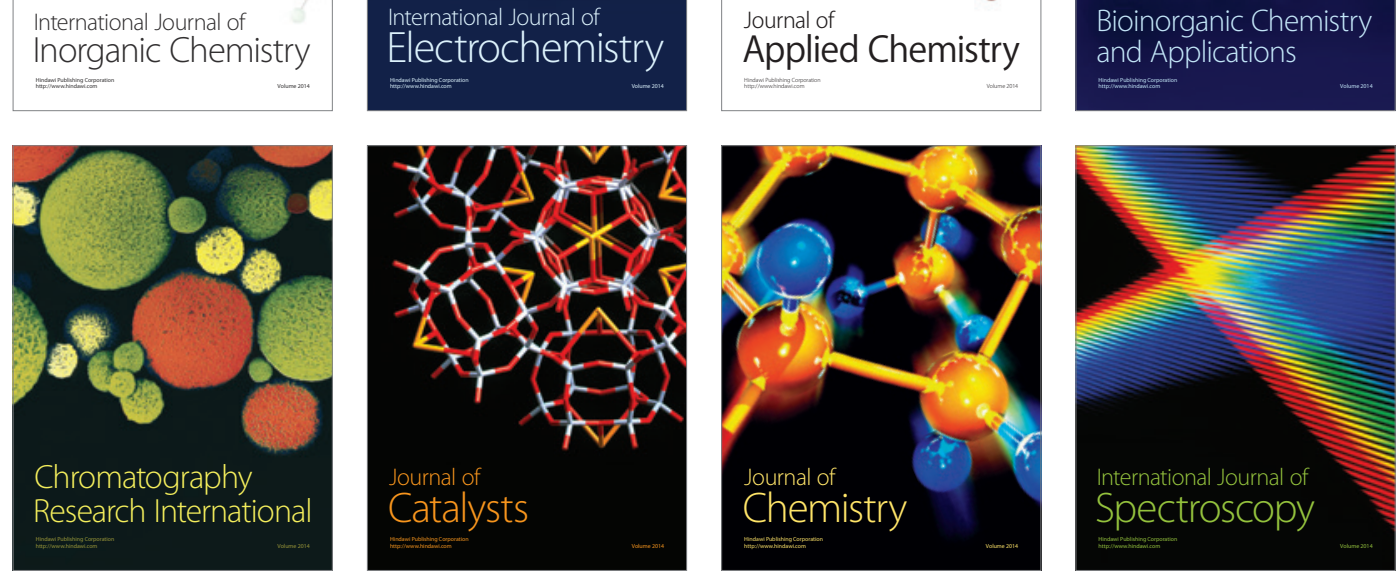